\title{
Trends, Management Patterns, and Predictors of Leaving Against Medical Advice among Patients with Documented Noncompliance Admitted for Acute Myocardial Infarction
}

\author{
Gbolahan O. Ogunbayo, $M D^{1,2}$, Tara A. Shrout, BA ${ }^{1,2}$, Naoki Misumida, $M D^{7}$, \\ Ahmed Abdel-Latif, $\mathrm{MD}^{7}$, Susan S. Smyth, $M D P h D^{7}$, Adrian W. Messerli, MD', and Khalid M. Ziada, \\ $M D^{7}$ \\ 'University of Kentucky Medical Center, Lexington, KY, USA; ${ }^{2}$ Division of Cardiovascular Medicine, The Gill Heart and Vascular Institute, \\ University of Kentucky, Lexington, KY, USA.
}

KEY WORDS: noncompliance; high-risk patients; leaving against medical advice (LAMA); acute myocardial infarction (AMI).

J Gen Intern Med 34(4):486-8

DOI: $10.1007 / \mathrm{s} 11606-018-4671-8$

(c) Society of General Internal Medicine 2018

\section{INTRODUCTION}

Noncompliance (NC) and leaving against medical advice (LAMA) are risk factors for poor outcomes, including hospital readmission and mortality. ${ }^{1,2}$ This study aims to investigate the relationship between $\mathrm{NC}$ and LAMA, describe characteristics of $\mathrm{NC}$ patients, evaluate the clinical management of acute myocardial infarction (AMI) in NC patients, and identify predictors of LAMA in this population. We hypothesized that NC would be associated with higher rates of LAMA.

\section{METHODS}

We identified adults with a primary diagnosis of AMI and documented NC using the National Inpatient Survey (2010 2014). Documented NC is defined by the ICD-9-CM Diagnosis Code V15.81 as a personal history of noncompliance with medical treatment, presenting hazards to health. We used logistic regression to perform temporal trend analysis for documented NC among patients with a primary diagnosis of AMI. We then compared demographic and clinical characteristics as well as outcomes, primarily LAMA, between this group and patients without documented NC. Weighted regression analysis was used to identify predictors of LAMA.

\section{RESULTS}

Of the 2,988,294 patients with a primary diagnosis of AMI, $4.7 \%(n=141,346)$ had documented NC. The incidence of NC increased from $3.9 \%$ in 2010 to $5.4 \%$ in

Published online November 6, 2018
2014 ( $p$ trend $<0.001$ ). The NC group was younger, more often male, and more likely to be black or Hispanic, was more likely to be uninsured or on Medicaid as well as have comorbidities including hypertension, diabetes, chronic pulmonary disease, and obesity. Rates of substance abuse and specific psychiatric disorders were significantly higher in the NC group.

LAMA was more than four times more likely in patients with NC (Fig. 1). Patients in the NC cohort were more likely to undergo coronary angiography or PCI, a finding that was due to a higher incidence of balloon angioplasty and not stent placement. They were also more likely to receive bare metal stents. In multivariate analysis, $\mathrm{NC}$ increased the risk of LAMA (OR 2.29, 95\% CI 2.09$2.5 ; p<.001)$, regardless of the type of AMI [STEMI (OR 2.42, 95\% CI 2.04-2.87; $p<.001$ ); NSTEMI (OR $2.22,95 \%$ CI $2.0-2.46 ; p<.001)]$. Male gender, current tobacco abuse, anxiety, adjustment and personality disorders as well as being on Medicaid insurance were all significantly associated with LAMA in the NC cohort, while interventions (coronary angiography, PCI, and CABG) were associated with a lower odds for LAMA (Table 1).

\section{DISCUSSION}

This study reports an increasing incidence of documented NC among patients (admissions) for AMI. As has been reported previously, ${ }^{1,3,4}$ we also found that young males of ethnic minorities and those with mental disorders have higher LAMA rates. Although there appears to be no bias against patients with $\mathrm{NC}$ with regard to intervention, practice patterns (i.e., stent placement versus plain old balloon angioplasty and bare metal stent versus drug eluting stent) may have been affected by medical compliance. This is a shift in previous knowledge of management patient with AMI that suggests lower rates of intervention in this patient population. ${ }^{1}$ 


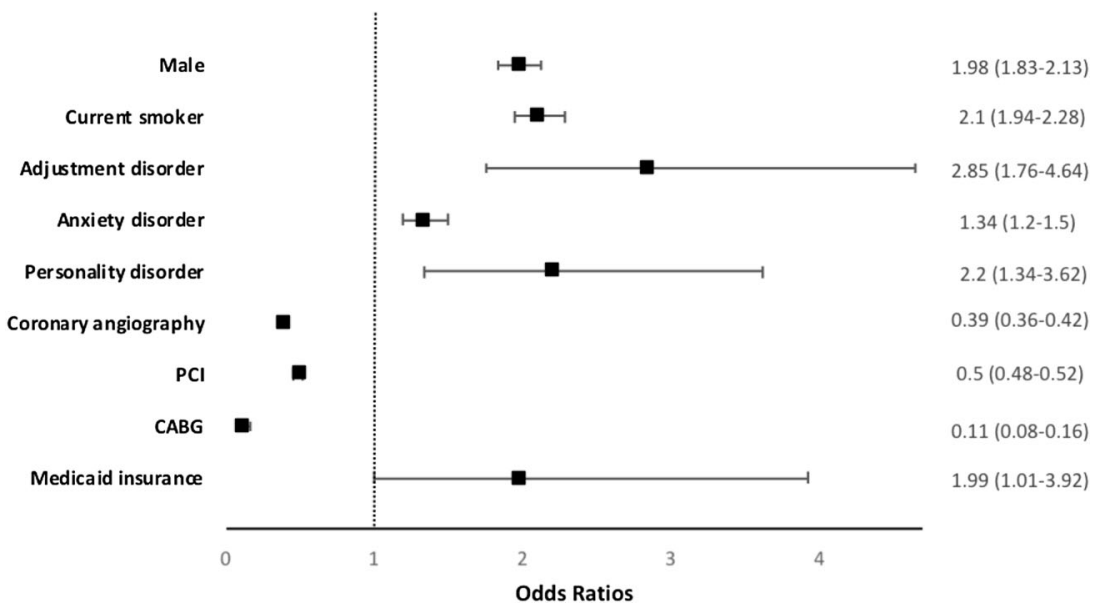

Fig. 1 Forest plot showing factors associated with LAMA in the NC population. PCI, percutaneous coronary intervention; CABG, coronary artery bypass grafting.

Our study suggests that NC is a strong predictor of LAMA. Early identification of patients at-risk for LAMA (males, tobacco users, personality disorders, low income) may prevent truncated care, hospital readmissions, higher health care costs, and mortality following AMI. Given recent studies that support shorter duration of dual antiplatelet therapy, ${ }^{5}$ we anticipate that practice patterns may also change. Better understanding of patient family issues, living situation, and previous medical experiences may also impact outcomes of this study and patient care. ${ }^{6}$

Table 1 Comparison of Factors in Patients With and Without Documented Noncompliance (NC)

\begin{tabular}{|c|c|c|c|}
\hline & Noncompliant $(118,037)$ & Others $(2,235,161)$ & $P$ value \\
\hline \multicolumn{4}{|l|}{ Demographics } \\
\hline Age & $59.6 \pm 12.8$ & $67.9 \pm 14.2$ & $<0.001$ \\
\hline Female & $36,444(30.9)$ & $889,746(39.8)$ & $<0.001$ \\
\hline Caucasian & $69,556(58.9)$ & $1,561,253(69.8)$ & $<0.001$ \\
\hline Black & $23,540(19.9)$ & $222,422(10)$ & $<0.001$ \\
\hline Hispanic & $12,092(10.2)$ & $169,591(7.6)$ & $<0.001$ \\
\hline \multicolumn{4}{|l|}{ Comorbidities } \\
\hline Hypertension & $92,911(78.7)$ & $1,596,251(71.4)$ & $<0.001$ \\
\hline Diabetes mellitus & $57,437(48.7)$ & $810,899(36.3)$ & $<0.001$ \\
\hline Chronic pulmonary disease & $27.631(23.4)$ & $463,342(20.7)$ & $<0.001$ \\
\hline Renal failure & $23,329(19.8)$ & $453,285(20.3)$ & 0.065 \\
\hline Obesity & $27,388(23.2)$ & $314,524(14.1)$ & $<0.001$ \\
\hline Current smoker & $53,529(45.3)$ & $511,964(22.9)$ & $<0.001$ \\
\hline Depression & $9855(8.3)$ & $170,022(7.6)$ & $<0.001$ \\
\hline Psychoses & $5577(4.7)$ & $53,046(2.4)$ & $<0.001$ \\
\hline Adjustment disorder & $410(0.3)$ & $4115(0.2)$ & $<0.001$ \\
\hline Anxiety disorder & $9023(7.6)$ & $153,708(6.9)$ & $<0.001$ \\
\hline Personality disorder & $438(0.4)$ & $1468(0.1)$ & $<0.001$ \\
\hline Alcohol abuse & $9726(8.2)$ & $65,067(2.9)$ & $<0.001$ \\
\hline Drug abuse & $10,629(9)$ & $48,823(2.2)$ & $<0.001$ \\
\hline \multicolumn{4}{|l|}{ Insurance } \\
\hline Medicare & $47,726(40.4)$ & $1,298,251(58.1)$ & $<0.001$ \\
\hline Medicaid & $17,832(15.1)$ & $144,254(6.5)$ & $<0.001$ \\
\hline Self-pay & $17,625(14.9)$ & $131,570(5.9)$ & $<0.001$ \\
\hline \multicolumn{4}{|l|}{ Management } \\
\hline Coronary angiography & $82,846(70.2)$ & $1,493,239(66.8)$ & $<0.001$ \\
\hline PCI & $54,648(46.3)$ & $1,006,638(45.0)$ & $<0.001$ \\
\hline Stent placement & $48,897(41.4)$ & $933,130(41.7)$ & 0.374 \\
\hline Bare metal stent placement & 18,909 (16) & $251,210(11.2)$ & $<0.001$ \\
\hline Plain old balloon angioplasty & 5751 (4.9) & $73.508(3.3)$ & $<0.001$ \\
\hline $\mathrm{CABG}$ & 7759 (6.6) & $153,044(6.8)$ & 0.148 \\
\hline \multicolumn{4}{|l|}{ Disposition } \\
\hline Routine discharge & $80,540(68.2)$ & $1,341,797(60)$ & $<0.001$ \\
\hline Left against medical advice & $4359(3.7)$ & $18,168(0.8)$ & $<0.001$ \\
\hline Died during hospitalization & $2746(2.3)$ & $118,671(5.3)$ & $<0.001$ \\
\hline
\end{tabular}

PCI, percutaneous coronary intervention; $C A B G$, coronary artery bypass grafting 


\section{CONCLUSION}

The incidence of NC in patients admitted with an AMI was higher in young, black and Hispanic males, and low-income patients with Medicaid or no insurance. NC patients were significantly more likely to LAMA. Predictors of LAMA in this population included current tobacco abuse and adjustment, anxiety or personality disorders, and being insured by Medicaid.

Corresponding Author: Gbolahan O. Ogunbayo, MD; Division of Cardiovascular Medicine, The Gill Heart and Vascular Institute University of Kentucky, Lexington, KY, USA (e-mail: Gbolahanogunbayo@yahoo.com).

\section{REFERENCES}

1. Fiscella K, Meldrum S, Barnett S. Hospital Discharge against Advice after Myocardial Infarction: Deaths and Readmissions. Am J Med. 2007;120(12):1047-1053. https://doi.org/10.1016/j.amjmed.2007.08.024
2. Garland A, Ramsey CD, Fransoo R, Olafson K, Chateau D, Yogendran M, Kraut A. Rates of readmission and death associated with leaving hospital against medical advice: A population-based study. Can Med Assoc J. 2013. https://doi.org/10.1503/cmaj. 130029

3. Jeremiah J, O'Sullivan P, Stein $\mathbf{M}$. Who leaves against medical advice? J Gen Intern Med. 1995;10(7):403-405. https://doi.org/10.1007/ BF02599843

4. Ibrahim SA, Kwoh CK, Krishnan E. Factors associated with patients who leave acute-care hospitals against medical advice. Am J Public Health. 2007;97(12):2204-2208. https://doi.org/10.2105/AJPH.2006.100164

5. Gargiulo G, Windecker S, da Costa BR, Feres F, Hong MK, Gilard M, Kim HS, Colombo A, Bhatt DL, Kim BK, Morice MC, Park KW, Chieffo A, Palmerini T, Stone GW, Valgimigli M. Short term versus long term dual antiplatelet therapy after implantation of drug eluting stent in patients with or without diabetes: systematic review and meta-analysis of individual participant data from randomised trials. BMJ. 2016:i5483. https://doi.org/10.1136/bmj.i5483.

6. Alfandre D. Reconsidering against medical advice discharges: Embracing patient-centeredness to promote high quality care and a renewed research agenda. J Gen Intern Med. 2013. https://doi.org/10.1007/s1 1606-013-2540-Z 